\title{
Estéticas en plural. La moda popular en Bogotá
}

\author{
Edward Salazar
}

Universidad de los Andes, Bogotá, Colombia

ef.salazar35@uniandes.edu.co

Resumen: Este artículo presenta los resultados y las reflexiones de la investigación sobre la moda, la estética y la indumentaria en los sectores populares en Bogotá durante el 2011 y el 2012, realizada por medio de técnicas cualitativas como el análisis de la imagen, la observación etnográfica y la entrevista. El propósito es analizar las distancias y acercamientos que existen entre la moda popular y la moda hegemónica para dar cuenta de la necesidad de hablar de las modas, pues existen diferentes visiones estéticas que un concepto singular no recoge. La moda popular toma, reinterpreta y problematiza la cultura material de la indumentaria producida por la moda hegemónica, a la vez que produce sus propios referentes que deben ser considerados como moda por cumplir con las premisas fundamentales del concepto, develando la preconcepción de clase que existe sobre este tema.

Palabras claves: Cultura popular; indumentaria; hegemonía; consumo; estética.

\section{Aesthetics in plural. Popular fashion in Bogotá}

Abstract: This paper presents the results and considerations of my research on fashion, aesthetics and garments in Bogotá's popular sectors during the 2011-2012 period, carried out through qualitative measurement techniques such as image analysis, ethnographic observation and interviews. The purpose is to analyze gaps and encounters between popular and hegemonic styles to explain the necessity of a conversation about

Cuadernos de Antropología

Enero-Junio 2016, 26(2), 51-68

DOI: $10.15517 /$ cat.v26i2.26493

Recibido: 31-03-2016 / Aceptado: 08-09-2016 / Publicado: 13/12/2016

Revista del Laboratorio de Etnología María Eugenia Bozzoli Vargas

Escuela de Antropología, Universidad de Costa Rica

http://revistas.ucr.ac.cr/index.php/antropologia

ISSN 2215-356X 


\begin{abstract}
types of fashion, and pointing out the existence of different aesthetic views that can't be described by a singular concept. Popular fashion takes, reinterprets and challenges the material culture produced by hegemonic fashion, simultaneously producing it's own references that must be considered as fashion because of it satisfies the premises of the concept. It reveals the class preconception that exist on the subject.
\end{abstract}

Keywords: Popular culture; attire; hegemony; consumption; aesthetic.

La moda es un repertorio de objetos concretos que circulan en contextos determinados, es decir un conjunto de bienes materiales cargados de interpretaciones históricas de la cultura. Se trata de una experiencia sensorial que educa la percepción estética de las sociedades de acuerdo a las particularidades de cada época. Por ello es necesario recodar la materialidad de la moda porque la moda son prendas, marcas, lugares, colores, texturas, modos de organizar y de significar traducidos en objetos y espacios. Esos modos de organizar son diversos, polivalentes. El vestido de cada persona siempre deja en otra persona una impresión singular y clasificable del otro, de sus valores, su procedencia social, sus aspiraciones individuales y colectivas.

El propósito de este artículo es hablar de las estéticas de la moda y el vestido en los lugares de comercio de los sectores populares de Bogotá, la moda popular, dentro y fuera del sistema hegemónico de la moda como aquel de los productores legítimos de la cultura. Presentaré una aproximación teórica a la moda como hegemonía y a la comprensión de los sectores populares, para luego entrar al análisis de lugares y objetos de la moda popular (su materialidad) y finalmente cerrar con la idea de que la moda popular existe y por ello hay que hablar en plural: las modas.

\title{
Metodología y trabajo de campo
}

Esta investigación fue financiada mediante convocatoria pública por el Departamento Administrativo de Ciencia, tecnología e Innovación de Colombia (Colciencias) en convenio con la Universidad Nacional de Colombia, en el marco del Programa Jóvenes Investigadores e Innovadores "Virginia Gutiérrez de Pineda" 2011 ${ }^{1}$. El trabajo de campo que alimenta esta investigación es principalmente etnográfico, en tanto se basa en recolección de datos de campo de carácter cualitativo por medio de la observación directa y sistemática. El trabajo se desarrolló en la ciudad de Bogotá, Colombia, en los últimos cuatro meses del año 2011 y los primeros dos del 2012. Se enfocó en los sectores Súper Manzana 4 y 7 en la localidad de Kennedy (Kennedy Central), y Las Ferias en la localidad de Engativá en Bogotá (Figura 1). Kennedy está ubicada en el sur-occidente y Engativá en el nor-occidente de la ciudad, catalogados principalmente como localidades compuestas por sectores medios y populares en términos socioeconómicos.

1 Agradezco especialmente al profesor Oscar Iván Salazar Arenas del Departamento de Sociología de la Universidad Nacional de Colombia, mi tutor durante esta investigación.

Cuadernos de Antropología 2016, 26(2), 51-68 / ISNN 2215-356X

http://revistas.ucr.ac.cr/index.php/antropologia 


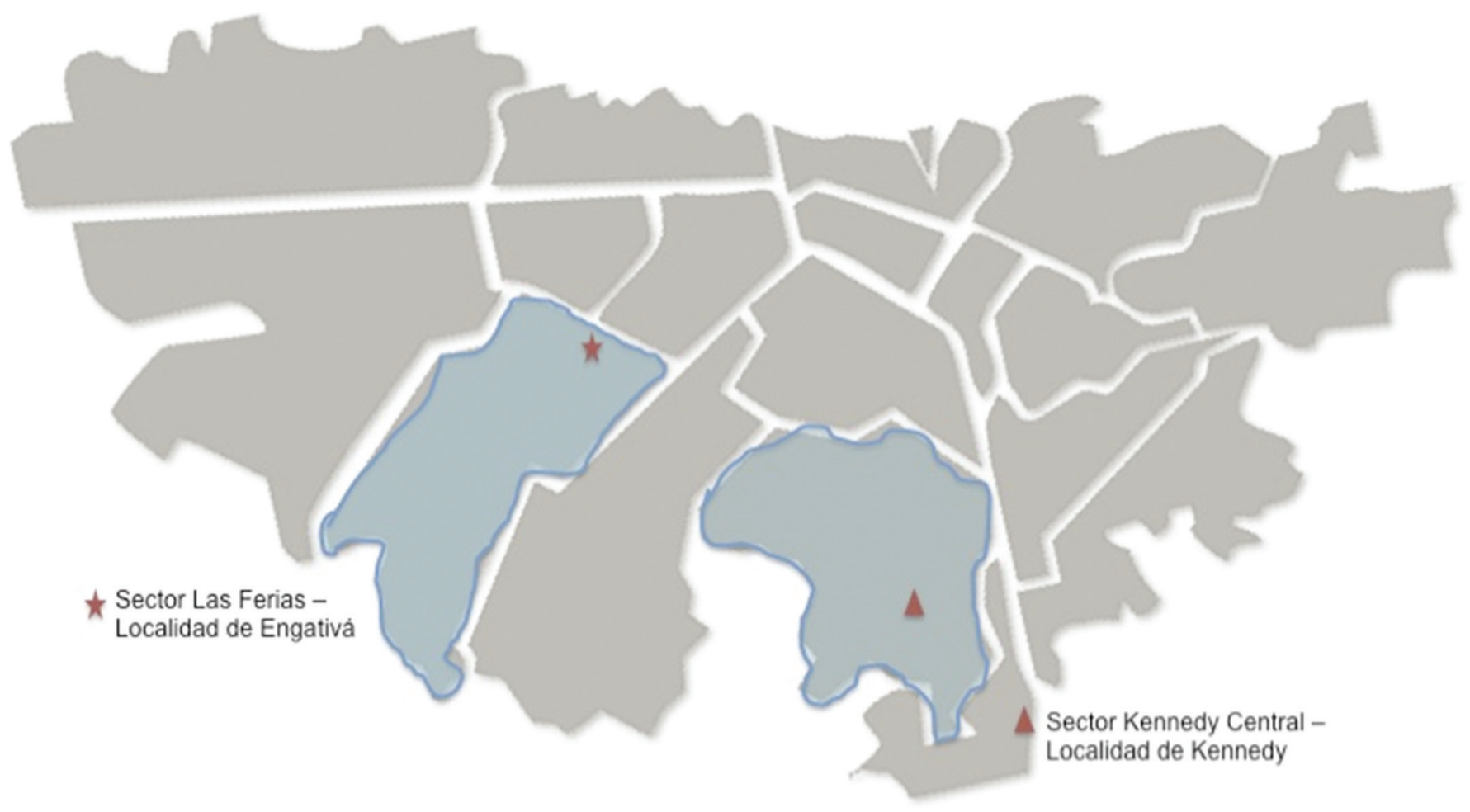

Figura 1. Ubicación cartográfica de los puntos en las localidades de Kennedy y Engativá en Bogotá, Colombia.

Los dos sectores fueron seleccionados dentro de las localidades por tener zonas reconocidas de comercio popular (formal e informal), con características espaciales y poblacionales similares, lo que permite controlar las variables de la muestra, a la vez que ofrecer un panorama más amplio y comparativo en Bogotá. En los dos sectores tomé fotografías a las vitrinas, las calles, los letreros, las tiendas y las prendas; llevé un diario de campo para sistematizar las observaciones, que fueron contrastadas con observaciones posteriores a comienzos del 2013.

Realicé dos entrevistas a profundidad: una al encargado visual de una tienda de moda reconocida en la ciudad y otra a una diseñadora de modas bogotana, con el propósito de indagar en el tema de la moda a través de las opiniones profesionales de dos personas altamente especializadas en el campo de la moda, para brindar una perspectiva local a la moda. Para contrastar estas opiniones profesionales, realicé otras cuatro entrevistas a vendedores de los sectores seleccionados y una entrevista a un distribuidor mayorista del centro de Bogotá, con el fin de cruzar los saberes profesionales de la moda hegemónica con los saberes prácticos de la moda popular. 
En suma, este trabajo empleó metodologías cualitativas para la recolección de la información, abogando por una mirada interseccional entre la observación del investigador, el análisis de los datos visuales y el análisis de contenido de los conocimientos entre quienes trabajan en las diferentes caras de la moda en Bogotá. La totalidad del trabajo de campo desarrollado mediante la beca de Colciencias hace parte del presente documento resultado de investigación.

Antes de continuar con el desarrollo de esta investigación, es importante dar al lector un breve contexto sobre la moda colombiana, que guarda una estrecha relación con la historia y el desarrollo de la industria textil. La industria cafetera y la de los textiles fueron bastiones fundamentales para el desarrollo económico del país durante el siglo XX, aunque la industria textil pierde su fuerza a partir de los años sesenta, cuando se desmonta paulatinamente el proteccionismo a la industria nacional. Aunque durante la segunda mitad del siglo XX la moda se equiparó con las telas, ellas no son sinónimos aunque hagan parte del mismo universo.

Es interesante notar cómo el declive de la industria textil en términos económicos y de representación de identidad nacional decae al tiempo que, en el país y a nivel global, se posicionan los discursos sobre la moda como eje regidor de apariencia de los ciudadanos (Salazar, 2014). Apegados al discurso de la importancia de la materialidad del textil sobre la apariencia de las prendas, la moda en Colombia no encuentra la fortaleza necesaria para consolidarse al nivel de otros países latinoamericanos como México, Brasil o Argentina. En todo caso, a partir de los años setenta se posicionan los principales diseñadores (como Tobby Setton), y una idea de moda muy relacionada con la emulación de la moda internacional (europea y estadounidense), aunque con algunos atisbos de posicionar en la moda ciertas ideas de identidad nacional.

Durante los años noventa toman fuerza las marcas y la producción nacional, con marcas como Armi, Pronto, Arturo Calle, Studio F, entre otras. Estas tiendas nacionales se posicionan hasta actualidad como las más reconocidas, dejando atrás aquellas existentes hasta los años 80 del siglo XX. Esta es la cara masiva de la moda, pero para hablar del desarrollo de la moda popular, haría falta una investigación a profundidad, relacionada con el desarrollo de los mercados populares de San Andresito (bodegas mayoristas en el centro de Bogotá) y de ahí todas las ramificaciones posibles de la moda de la calle popular, que este trabajo no puede abarcar.

\section{Encuentros y distancias: lo popular, lo masivo y la moda}

Para Descamps (1986) “[...] la moda es una sucesión ininterrumpida y rápida de difusiones súbitas, sin más razón que ellas mismas y de índole efímera.” (p. 19), que incluye todo el conjunto organizado y cíclico 
de circulación de objetos e ideas estéticas. Abarca su producción, distribución, presentación, consumo y su consiguiente renovación o reciclamiento. A este funcionamiento ordenado y estricto de signos es a lo que Barthes (2003) llama el sistema de la moda: crea sus propias funciones (desfiles, revistas, colecciones, etc.) con el fin de reproducir sus signos y consolidar un sistema retórico.

Pensadores como Hertebert Bummer (1969) o Mary Douglas (1997), entre otros, consideran la moda y las decisiones estéticas como un problema tanto de selección colectiva como de decisión individual. Otros como Simmel (2002) o Bourdieu (1998), identifican en la moda un elemento diferenciador de clase social. Bajo estas dos miradas, la moda reviste una doble característica: diferenciadora la clase social y proceso colectivo e individual de selección estilística.

Como fenómeno cíclico, masivo e individual, la moda es posible porque la actual sociedad de producción permite la creación de mercancías a bajos $\operatorname{costos}^{2}$, marco en el cual vivir con estilo o estar a la moda se vuelven proyectos tanto de las élites como de masas populares. Se trata, entonces, de una sociedad de consumo que permite "hacer soñar a los pobres el mismo sueño de los ricos" (Martín-Barbero, 1987, p. 179). Esta expresión de Barbero se refiere tangencialmente a la propuesta de análisis para esta investigación: el sueño de los ricos es la hegemonía.

Para este caso, entiendo la moda como un conjunto de valores hegemónicos (aunque coyunturales y contingentes) articulados por los medios, la distribución de las mercancías y las prácticas de consumo, que formulan una moda que impera sobre cualquier otra forma de vestirse. García-Canclini (2004) define la hegemonía como:

...un proceso de dirección política e ideológica en el que una clase o sector logra una apropiación preferencial de las instancias de poder en alianza con otras clases, admitiendo espacios donde los grupos subalternos desarrollas prácticas independientes y no siempre "funcionales" para la reproducción del sistema (p. 72).

Así, la hegemonía en la moda produce y reproduce el sistema de signos y contenidos estéticos que son pensados como superiores y por ello apropiables, a la vez que abre el espacio a otros consumos y producciones subalternas que dialogan, rompen, intervienen o dejan intacta dicha hegemonía.

2 En el caso de la moda, el ejemplo más claro es el sistema internacional de maquila, que, a través del abaratamiento de la mano de obra en ciertos países y la importación de materias primas a menores costos, hacen posible fabricar ropa en serie y con costos de producción igualmente bajos. 
La moda hegemónica se materializa en estilos, prendas y accesorios (objetos absolutamente concretos) que son ofertados de maneras específicas en los lugares de comercio de los sectores populares como uno de los escenarios de lo subalterno. En dichos sectores la moda articula relaciones de resistencia, dominación y subordinación cultural por medio de la más específica copia o la reinterpretación más radical de la cultura material hegemónica.

Lo popular puede entenderse como un lugar particular dentro de la estructura social de clases. Dicha estructura opera para el sociólogo Pierre Bourdieu (1998) como un mapa cartesiano en donde cada coordenada está signada por la cantidad y calidad que se posea de capital social, económico y cultural. La disposición de estos capitales conforman el habitus: el lugar aprendido de las prácticas sociales. El habitus establece "[...] una relación inteligible y necesaria entre unas prácticas y una situación de las que el propio habitus produce el sentido con arreglo a categorías de percepción y apreciación producidas a su vez por una condición objetivamente perceptible" (Bourdieu, 1998, p. 99).

El habitus se materializa en prácticas y gustos que se pueden catalogar y valorar para establecer diferencias entre lo legítimo y lo subordinado, entre los dominantes y los dominados. En este caso, el habitus popular marcará una relación específica con la moda hegemónica. Aquí lo popular estaría del lado de lo dominado porque sus prácticas están signadas por bajos niveles de capital social y económico, pero especialmente por la baja posesión del capital cultural hegemónico. La investigación realizada por Bromberg, P. y Gomescásseres (2010) sobre los sectores urbano-populares de Bogotá, analiza lo popular desde sus connotaciones de clase pero señalando que la clase no puede definir lo popular: es ante todo un campo, en el sentido de Bourdieu (1998), dinamizado y complejizado por las particulares relaciones económicas, culturales y sociales. En el campo de lo popular "lo sagrado, lo profano, lo familiar, lo barrial, lo ciudadano y cosmopolita, lo legal, lo ilegal, se confunden, coexisten y dinamizan estrategias de supervivencia, hábitos, imaginarios, formas de sociabilidad y de trabajo, usos, costumbres y convenciones" (Bromberg, P. y Gomescásseres, 2010, p. 70).

Stuart Hall entiende lo popular como una formación que echa raíces en las condiciones sociales y materiales de las clases subalternas, incorporadas a tradiciones y prácticas llamadas populares con efectos culturales concretos (Hall, 1984, p. 6). Hall analiza la visión antropológica de lo popular (aquella que tiene en cuenta el papel de la tradición y del elemento de lucha de clases) con la visión de lo popular como consumo de masas, para decir que no existe algo como una cultura popular autónoma, auténtica y completa que no circunscriba sus prácticas dentro de relaciones hegemónicas de dominación y poder. 
Hay una lucha continua y necesariamente irregular y desigual, por parte de la cultura dominante, cuyo propósito es desorganizar y reorganizar constantemente la cultura popular; encerrar y confinar sus definiciones y formas dentro de una gama más completa de formas dominantes. Hay puntos de resistencia; hay también momentos de inhibición. Ésta es la dialéctica de la lucha cultural (Hall, 1984, p. 5).

Hablar de lo popular y de la cultura popular también implica hacerlo desde su relación con la cultura de masas, es decir, con las ideas y los objetos que por su producción y consumo masivo superan una gran cantidad de barreras de circulación y se instalan especialmente en los sectores sociales de clases medias y altas. Es importante saber que lo masivo en la moda entra dentro de lo que he llamado hegemónico: una estandarización cultural acordada por los diferentes sectores que hacen parte de la moda.

Martín-Barbero reconstruye la relación de lo popular con lo masivo para no confundir lo popular con lo folclórico, lo pasado o lo rural y así evitar verlo como polo opuesto de los procesos de masa (Martín-Barbero, 1987). La masificación como nueva episteme de las relaciones sociales implica tener en cuenta que "pensar lo popular desde lo masivo no signifique, no deba significar al menos automáticamente alienación y manipulación, sino unas nuevas condiciones de existencia y de lucha, un modo nuevo de funcionamiento de la hegemonía" (Martín-Barbero, 1987, p. 249).

Bajo estas perspectivas, entiendo lo popular necesariamente desde su dimensión espacial, sus profundas relaciones con las condiciones materiales de la producción en masa, la capacidad económica de los sujetos y las prácticas activas de los sujetos: habitus, hegemonía y cultura popular, todo en acción.

Aunque los gustos en la apariencia varían de acuerdo a la clase social y están dirigidos a la aspiración de superioridad pactada por la hegemonía de la moda en las revistas o en los centros comerciales, la moda también contribuye a la popularización de los productos estilizados que desdibujan algunas diferencias sociales. Ambiguamente, permite que el sujeto exprese libremente sus deseos a la vez que se promueve la participación dentro de un conjunto de valores hegemónicos. La moda es un claro ejemplo de "una cultura que en vez de ser el lugar donde se marcan las diferencias sociales pasa a ser el lugar donde esas diferencias se encubren, son negadas" (Martín-Barbero 1987, p. 134). 
La moda sigue constituyendo un orden estético rígido y por ello las producciones estilísticas de los sectores populares son vistas de maneras peyorativas. Sirve de ejemplo la definición de lo popular que hacen los jóvenes bogotanos que entienden por popular aquella ropa o estilos que han llegado a tan alto nivel de masificación o de reinterpretación que es usada por los "ñeros" (calificativo despectivo) o por quienes quieren estar a la moda sin ningún criterio estilístico correctamente formado (Salazar, 2009). Lo que podría verse como reinterpretaciones y formas activas de participación en el consumo, también se lee en un tono despectivo para asumir lo popular como producción inferior.

Si existe una moda hegemónica, no debería hablarse de cultura popular en general sino de la moda popular en particular. Debe hablarse de las modas y no de la moda.

\section{La calle y las tiendas de vestido en los barrios populares}

En las zonas comerciales populares estudiadas para esta investigación (ver Figura 1), los andenes peatonales se repletan con las ventas informales. Las mercancías se disponen en trapos y plásticos tirados en el suelo, en estantes, en carretas, colgados al cuerpo de vendedores y vendedoras. Cualquier estructura puede ser un aparador. Con esta saturación, el comercio ambulante hace lenta la circulación de las personas porque las calles se estrechan. Locales formales también llevan parte de sus negocios a la calle: saben que la calle llama, y ubican maniquíes, estantes, vitrinas y todo tipo de aparatos para la exposición de ropa más allá de la puerta de sus locales.

En las calles hay un espectro amplio de objetos ofertados, aquellos estables, y aquellos que cambian de acuerdo con el momento de la "vida social": una temporada de fútbol, merchandising de una película, la temporada escolar, Halloween o Amor y Amistad. También son momentos asociados a la novedad, como una película o determinadas prendas de moda. La novedad tiene la función social de dirigir la mirada hacia lo distinto, "lo que pretende atraer nuestra atención, despertar nuestro interés, intensificar nuestra emoción interior, debe destacar de alguna manera de lo evidente, lo cotidiano, lo que interior y exteriormente nos es habitual" (Simmel, 2002, p. 63). Lo nuevo también es principio de oportunidad económica, ya que los vendedores ambulantes tienen en sus puestos las mercancías de la temporada porque son las que más les aseguran ganancias. Como la novedad tiene valor para productores, vendedores y consumidores, el mercado se satura de las tendencias, de las cosas que cumplen la función matemática de ser las más vendidas. La moda estadística, que por supuesto coincide con la moda hegemónica.

Con todo, la circulación de mercancías no es plana. La novedad hegemónica está previamente modelada pero no es unidireccional. Los productos toman múltiples caras en el proceso de distribución popular. Por ejemplo, los fabricantes alteran ciertos detalles, cortes o colores en las prendas, accesorios y zapatos, para crear productos que tengan el halo estético de antes fueron muy vendidos pero insuflados con una 
impresión de novedad. Al lado de la feria de la novedad coexisten las prendas y accesorios que tuvieron poco éxito en temporadas anteriores y ahora se amontonan en pilas de chaquetas, en paredes rebozadas de camisetas o blusas que poco a poco se van vendiendo. También se mantienen en circulación prendas básicas como pantalones oscuros, sacos de rayas, tenis estilo Converse, chaquetas impermeables, correas sintéticas y en general todo tipo de prendas menos susceptibles a los rápidos cambios de la moda. Llevan años allí, aunque la moda hegemónica ya las haya descartado. El rezago coexiste con el éxito y muchas veces se confunden entre sí. La calle lee la moda porque los vendedores son tácticos y cazan furtivamente para aprovechar sus cambiantes ocasiones.

Armando Silva (2006) habla de esta saturación en las calles urbanas: diferentes expresiones culturales, especialmente aquellas que puedan considerarse disidentes, permiten a los ciudadanos construir rutas e imaginarios de ciudad laberínticos, salidos de alguna rejilla que los codifique en una sola dirección. En la calle popular de Kennedy y Engativá todo es hiperbólico, se hace notar, y por eso si uno quisiera encontrar qué está de moda como patrón estético en el vestido, en el mobiliario o en cientos de objetos, hay que volcar la mirada a la calle. La calle y las ventas informales son vitrinas de la moda. Las calles de comercio dejan como impresión la invasión, el desorden y la saturación (Figura 2). Los productos se disponen en sintonía con las precariedades del espacio, de las estructuras para exhibir y de las necesidades de presentar la mayor cantidad posible de mercancía: es la presentación simultánea de lo popular y de la moda hegemónica.

Ante la cantidad de mercancías bajo la pluralidad estética, hay que tener en cuenta dos hechos. El primero, que los estilos populares también son moda porque cumplen con los preceptos de función estética y venta en masa; el segundo, que la moda hegemónica no puede garantizar la exclusividad sino a través del refinamiento de las tecnologías de producción (telas, detalles o acabados) o de enunciación (marcas o logos). Por ello la moda no es un sistema unificado que opera exclusivamente "desde arriba". Los procesos populares también generan moda. Usar pantalones ataviados con brillantes de plástico también está de moda, así a la moda hegemónica le incomode y por ello no incluyan dicho estilo dentro de su distribución mediática.

"Juventud" es un local pequeño ubicada en el primer piso de una casa familiar del barrio Manzana Cuatro en la localidad de Kennedy. Vende ropa para mujeres que la dueña compra en San Andresito ${ }^{3}$ o en distintos mayoristas del centro de Bogotá (Figura 3). En "Juventud" las mercancías se exponen en una ventana, en algunos maniquíes sin cabeza y en una vitrina similar a las que hay en las tiendas de dulces. En esta vitrina exhibe las prendas, dobladas unas sobre otras, lo que las hace poco diferenciables entre sí. Sin embargo es posible distinguir sus características estéticas cuando la vendedora las enseña al detalle. Otros locales, como los ubicados en la plaza de mercado de Las Ferias, tiene una lógica de presentación parecida a la de la calle: total saturación de productos en el suelo, paredes, aparadores, canastas, maniquíes colgados

3 Sector popular de comercio mayorista en Bogotá, donde las personas, pero especialmente los dueños de pequeños negocios, acuden a comprar mercancías por docenas a mejores precios, muchas veces accediendo a mercancías de contrabando. 


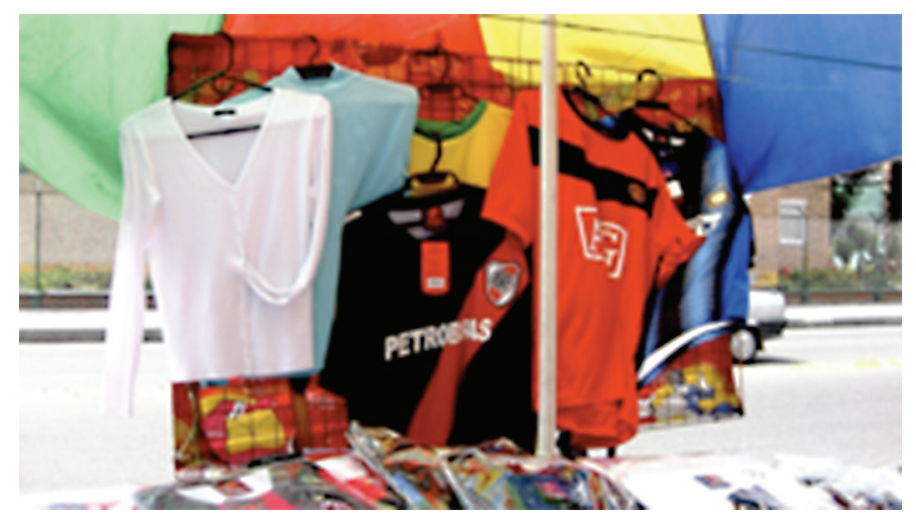

Figura 2. Disposición de las mercancías en la calle en Kennedy. Va desde la venta de básicos (cárdigan blanco) hasta las camisetas de fútbol de la temporada.

o puestos en la calle al frente de los locales que dan hacia el andén. No hay acá una identidad de tienda, sino de pequeños espacios para comprar. Estos locales tienen, además, la misma dinámica de la calle por su carencia de nombres propios.

De otro lado, "Kenzo Jeans" es una tienda muy conocida en Bogotá, ubicada en bastantes barrios y centros comerciales de clase media (Figura 4). Ofrece productos de moda para mujeres, hombres, niños y niñas, con precios que van entre los 50 mil y los 150 mil pesos colombianos ${ }^{4}$, lo que la hace una de las tiendas más caras en Kennedy y Engativá. "Kenzo" remodeló sus espacios para estar a la moda moda arquitectónica de las tiendas de moda hegemónica: color negro, grandes ventanales como vitrinas, bastante iluminación interior y estantería metalizada o de imitación madera. Y, sin embargo, Kenzo es una tienda popular.

La tienda (entendida como lugar de comercio dentro de edificaciones formales) es otra cara de la presentación de la moda en los barrios populares, y producen impresiones estéticas diferentes a las que produce el local de la calle. En estos sectores, las tiendas y los locales tienen nombres que pueden ser leídos como "de marca" o como simples referencias de ubicación, y relacionalmente con el nombre las tiendas varían sus grados de orden en la presentación de las mercancías. Estos tres elementos hablan de las relaciones de lo popular con lo hegemónico, pues en los barrios populares las impresiones estéticas mezclan lo reconocible de una tienda con lo irreconocible de un local. El local es general mientras la tienda es particular.

La mayoría de las tiendas tienen nombres propios identificables por los avisos puestos en las facha-

4Al cambio de mayo del 2016, 50 mil y 150 mil pesos colombianos equivalen aproximadamente a US\$16,3 y US\$ 49,1, respectivamente. Estos precios corresponden, en Colombia, a bienes de consumo en ropa y accesorios en un rango de precios estimados para un amplio sector de la clase media. Kenzo es un almacén masivo, no netamente popular. 


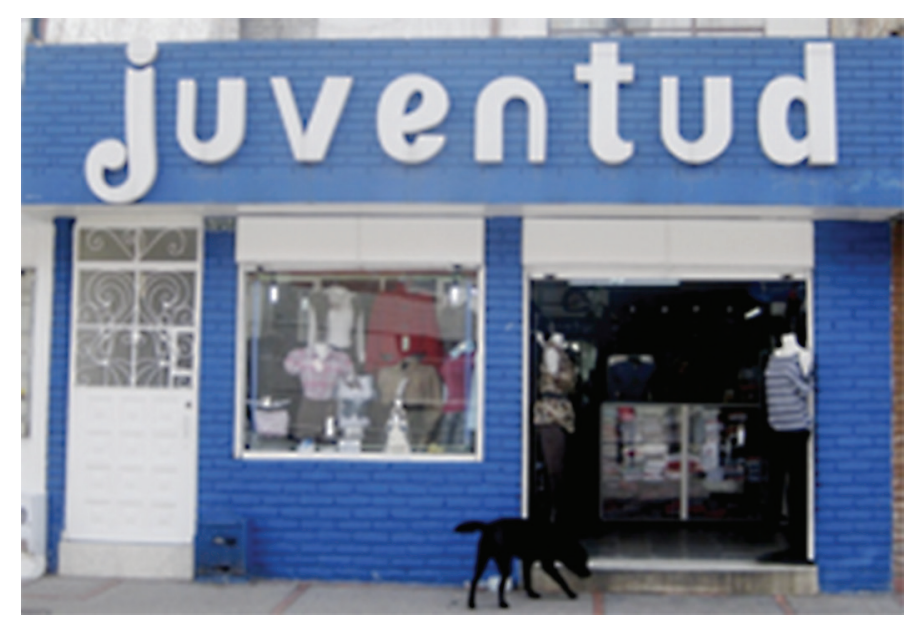

Figura 3. Fachada de la tienda "Juventud", en Kennedy.

das. Dichos avisos dan cuenta de la importancia que tiene la enunciación formal de la moda, dado que las palabras pueden llegar a producir los efectos invocados. El concepto de Austin (1982) de Oración realizativa es interesante para hablar de la manera en que las palabras dicen lo que hacen, sin que necesariamente puedan ser verificadas como hechos concretos. Aunque Austin está pensando en las palabras que se dicen y acá estoy pensando en las que se escriben, propongo entender los avisos de las tiendas como enunciados realizativos.

De acuerdo con Austin (1982), hay que pensar en elementos como el contexto en el que algo se dice, quién lo dice y lo qué dice, para dar cuenta del carácter realizativo de las palabras Austin habla de la autoridad que debe tener la persona que emite el enunciado realizativo, en el caso del bautizo de un barco: Quien dice "yo bautizo a este barco con el nombre...", es generalmente un capitán o un dueño que tiene dicha autoridad. Para este caso, en estos avisos comerciales son recurrentes las palabras moda, actualidad, diseño, exclusividad o juventud, debido a que los anunciantes que bautizan sus tiendas quieren vender moda. Las palabras no se quedan solamente en los avisos ya que los vendedores ratifican aquello que publicitan: "Nosotros [vendemos] moda, por algo será que este almacén se llama "Solo moda Sport" [...] Vendemos lo de moda; solo moda, todo lo que se está utilizando mucho para gomelos, menos para ñeritos, obviamente" (Vendedor de la tienda Solo Moda, comunicación personal, 13 de mayo de 2011)

La vendedora tiene la autoridad para decir "nosotros vendemos moda y por eso es que este local se llama "Solo moda"'. Esta autoridad de nombre hace que los vendedores se comprometan con la idea de moda en aquello que ofrecen, pese a que en estas tiendas predomine la lógica de la coexistencia de lo nuevo con lo viejo y obsoleto. La construcción visual del letrero también retrata lo popular: avisos nuevos, viejos o deteriorados prematuramente, que combinan gran cantidad de colores saturados, fondos prediseñados con estrellas, destellos o brillos, que en general dan la impresión estética de un pastiche de formas, colores, temporalidades y palabras. 


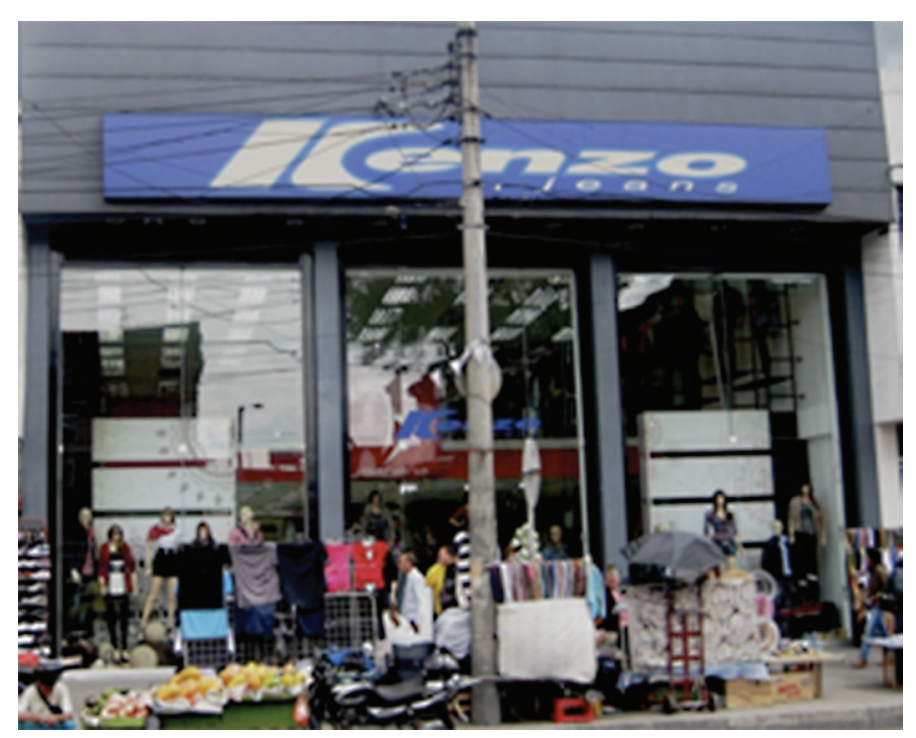

Figura 4. Fachada de la tienda "Kenzo", en Engativá. Lógicas coexistentes entre el amontonamiento de la calle y el orden de la gran tienda.

Mientras los nombres de algunos avisos son marcas (distinción), otros son tan solo referencias. Algunas marcas en estas zonas de comercios son reconocidas en Bogotá en tanto le apuntan a diferentes estratos socio-económicos, de las que se puede decir que son masivas-populares. Masivas por la cantidad de tiendas en la ciudad (más de tres) y populares ya que la distinción de clase no es su diferencial de venta. Por ejemplo, puede encontrarse una tienda de la marca pronto tanto en Kennedy como en el Centro Comercial Unicentro, cuyo público son personas con alto poder adquisitivo. Dentro de los barrios populares estas marcas cuentan con un amplio valor social reconocido por los vendedores populares y por las personas que las consumen, por estar relacionadas con moda y prestigio. Una marca que en estos contextos es muy valorada no lo es tanto en otras fracciones sociales, como el caso de Kenzo, Abril o Pronto.

En las tiendas populares el nombre propio se asocia con un lugar de precios bajos o como distribuidores de ropa de todas las procedencias. Es el caso de los almacenes Arequipe, Only, Atmosphere o Sanzo, en donde el nombre no se consume como una marca de prestigio, sino como una estrategia para obtener artículos a bajos precios. En ellos la moda no la hegemónica, sino que esta convive con expresiones de moda popular caracterizadas por el hiperadorno en la ropa.

Arequipe resulta un caso muy interesante para hablar de lo popular. A nivel enunciativo, la tienda usa como slogan la expresión "moda dulce". Moda habla de una cualidad específica asignada a las prendas y accesorios; dulce habla de lo colorido, lo grato, lo llamativo, incluso empalagoso. Moda dulce es entonces una suerte de retórica estética que ratifica la idea de saturación. Esta idea toma fuerza si se analiza el iden- 
tificador visual de Arequipe: sobre un fondo amarillo, las letras de la palabra arequipe están en distintos colores (naranja, azul encendido, rosado y verde, todas degradadas con blanco a la mitad), en una tipografía bold que da una impresión estética de rebose. Esta tienda realiza bazares de descuentos con animadores que anuncian desde la entrada de la tienda, hace rifas y contrata mujeres voluptuosas para repartir los premios; sus tiendas se componen de aparadores y canastas repletas de ropa en donde el espacio de tránsito es mínimo, sus vitrinas presentan versiones saturadas de la moda hegemónica y piezas inéditas en un ritual de amontonamiento que habla de lo popular.

\section{Gradaciones: la vida social de los objetos en la moda}

En su libro "El proceso de la civilización”, Norbert Elías señala que "la multiplicidad de cuestiones que plantean las diferencias y las gradaciones en el comportamiento de las clases altas, medias y bajas constituye un campo de estudio en sí mismo" (Elías, 1987, p. 466), y a continuación anota que si observamos:

[...] con mayor detenimiento una pequeña porción de este movimiento puede parecer que la diferencia entre la modelación emocional y el comportamiento de las clases superiores e inferiores del mundo civilizado es muy grande. En cambio, si se considera todo el movimiento a lo largo de los siglos, puede observarse una reducción continua de los contrastes agudos en el comportamiento de los diversos grupos sociales, al igual que en los contrastes y variaciones en el de los individuos aislados (Elías, 1987, p. 467).

La moda es un campo en donde esos contrastes se han reducido. En el campo de la apariencia muchas distancias se reducen gracias a la circulación amplia de los objetos/prendas en el mercado. Si bien la vida de los objetos es distinta en cada posición de la escala social, su apropiación pasa más por el "buen ojo" del consumidor que por la disponibilidad limitada, es decir el nivel de conocimiento que el sujeto debería tener si quiere adoptar la moda hegemónica. Pero más allá de eso, de lo que se trata es de mostrar las gradaciones que sufren los objetos cuando pasan de un grupo social a otro.

Esas gradaciones, que pueden ser reproducciones, adaptaciones y creaciones dan cuenta de la vida de los objetos en los sectores populares como estéticas de las similitudes y las distancias respecto a la hegemonía, pues los valores de una cultura dominante no le pertenecen a esa cultura sino que incluye a los sectores "dominados". Este es precisamente el espíritu de la hegemonía: "no consiste en la imposición de una visión cerrada al resto de la sociedad, sino en la articulación de múltiples elementos ideológicos que no tienen una necesaria connotación de clase, al discurso ideológico de la clase hegemónica" (Laclau, 1977, p. 20).

Reproducir y adaptar los patrones estéticos de la moda o la tendencia en el vestido son casos de la gra- 
dación estética en diferentes sectores sociales. En los comercios populares de ropa, la reproducción puede entenderse como la copia y venta ilegal de las marcas posicionadas de vestido y accesorios. En las calles o las tiendas se venden copias visualmente exactas de bolsos de Carolina Herrera, un gran número de diseños de tenis deportivos de marcas como Puma, Nike o Adidas, en donde la diferencia entre los legítimos y la copia radica en los materiales de fabricación, en el precio de venta y, en otro plano, en lo que subjetivamente implica comprar algo "original". La copia es uno de los mecanismos de acceso a los valores de la moda hegemónica, que no logra idénticas apariencias estéticas, pero que brinda a los sujetos la posibilidad de pertenencia al campo de la moda hegemónica, especialmente cuando las copias logran tan alto nivel de similitud con los objetos que reproducen.

Sin embargo, en la reproducción no se copian o venden todas las marcas. La mayoría de las prendas que se copian son casi siempre de marcas internacionales como Gap, Abercrombie \& Fitch, camisetas y jeans Armani, pantalones o chaquetas Diesel, tenis Nike o Adidas, entre muchas otras. No se encuentran copias de marcas de clase media como las ya mencionadas Abril, Pronto o Kenzo. Estas marcas no hacen parte del panorama de la moda hegemónica, además de tener precios más accesibles de los que tienen las marcas del primer grupo, por lo que su reproducción resulta un ejercicio inútil. Las marcas que se copian son aquellas con un valor más alto posicionado por la hegemonía de la moda, mientras que las otras masivas/populares no son susceptibles a la reproducción (Figura 5). Mientras que para algunas personas y vendedores en los sectores populares Pronto o Kenzo son referencias de prestigio, calidad y estatus, para otras personas y vendedores en el círculo hegemónico de la moda estas marcas son populares y sin mérito especial.

Pero la reproducción no es la única manera en que se presenta la gradación: adaptar/reformular es otra forma de filtración. La adaptación es un juego que parte una referencia para producir sin borrar la huella de la procedencia (Figura 6); se trata de adaptaciones como las que por ejemplo señala Sanín en su trabajo sobre los objetos en los sectores populares: del aceite Johnson al aceite Jefferson, reformular la apariencia del logo de una marca hasta lograr uno similar (Sanín, 2008).

Las adaptaciones pueden estudiarse en el caso de los jeans. El jean es una prenda ciertamente universal, su material es reconocible y su función de comodidad altamente aceptada. Los jean tradicionales de la hegemonía son prendas sencillas en su corte, confección, acabados y decoración, mientras que en los sectores populares el jean puede ser un lienzo para la saturación. En los sectores populares se venden jeans saturados con bordados, aplicaciones, desgastes, pliegues o aplicaciones: si un jean básico de color caramelo hace parte de la moda hegemónica, en la moda popular se puede encontrar con aplicaciones en los bolsillos de adelante y con una imagen de Hello Kitty en los de atrás.

En los sectores populares las prendas a la moda incluyen nuevos significantes que saturan y modifican el significado: si el animal print está de moda, habrán prendas tanto reproducidas con fidelidad como adaptadas desde los detalles. La figura 7 presenta una blusa en animal print de la moda de la moda popular 


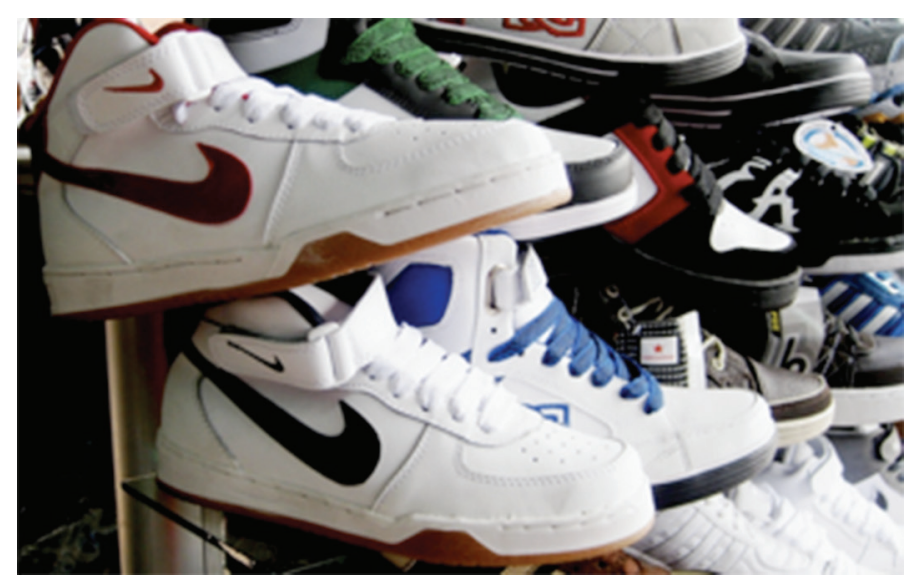

Figura 5. Copia idéntica de la apariencia de los de tenis Nike Clásicos, en los que cambia la calidad de los acabados. Se consiguen por el $60 \%$ menos del precio original.

(Figura 7), en donde en comparación a la hegemónica, la popular cambia el corte corte (cuello bandeja y sin mangas respecto al modelo aceptado de blusa con mangas y cuello camisero), acompañada de un accesorio muy difundido lo popular: un cinturón sintético. Ambas parten del principio de que está de moda el animal print, llegan a objetos diferentes pero en últimas hacen parte de la misma tendencia. Las adaptaciones como actos de incorporar reinterpretando valores hegemónicos ponen en duda la diferenciación social desde la apariencia.

De otro lado, la creación popular late también como un proceso autónomo de producción estética a través del uso de recursos culturales relativamente propios. Se trata de la materialización de objetos y estilos que están fuera de la moda hegemónica, que en sus tiendas y calles no se usarían, pero que en los sectores populares cumplen las premisas de la moda: caducidad, venta en grandes cantidades y por ende contar con adeptos, y tener amplia difusión en los mercados: estantes, aparadores, calles y maniquíes populares son saturados temporalmente con dichos estilos. Son objetos que escapan de los centros comerciales y las revistas de moda; son estilos no validados dentro de la hegemonía pero que claramente producen un relato de la moda popular.

En una temporada estuvieron de moda y fueron altamente vendidas las camisetas con la palabra "oe", extraída de una telenovela colombiana llamada Germán es el Man. Sucedió lo mismo con la manera de vestir a las niñas emulando el personaje de Antonella, antagonista de una popular serie argentina transmitida en Colombia llamada Patito Feo. También sucedió algo similar con la tendencia de las camisetas estampadas la cara de Elmo Cosquillas, uno de los personajes de la serie Plaza Sésamo. Las calles populares estuvieron llenas de estas creaciones así como de hombres y mujeres vestidas con ellas, y los vendedores testificaron su éxito: mayores ingresos para sus bolsillos a través de la comercialización efímera y completamente aparente. 

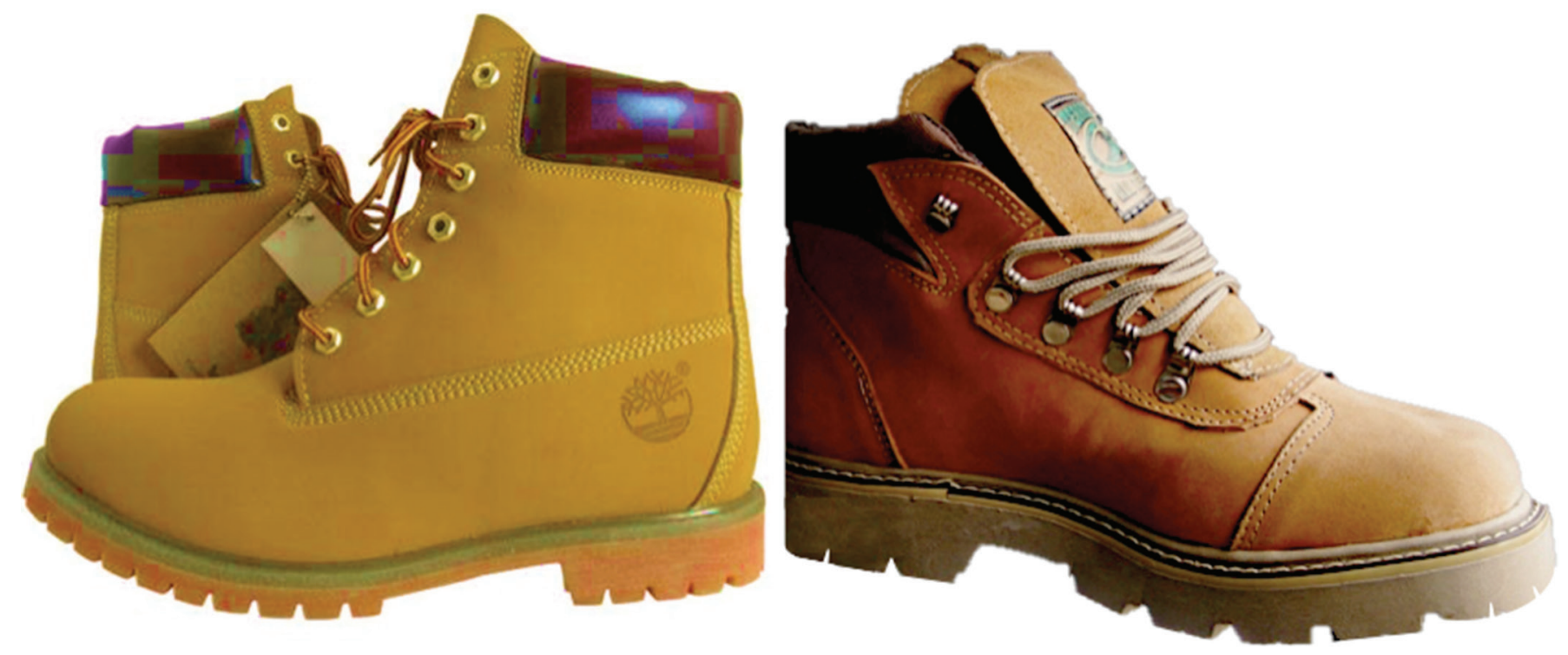

Figura 6. A la derecha, la reinterpretación de las botas Timberland de la izquierda (imágen bajo licencia Creative Commons 3.0) cambiando el color, el detalle de la lengua, los broches de los cordones y el tamaño de la suela, entre otros detalles.

En los comercios populares existen accesorios, estampados, cortes, prendas y un gran número de objetos que no son registrados por las revistas, los catálogos, los desfiles o los programas especializados en moda. Hay una gran producción cultural que habla de las relaciones entre lo popular, lo masivo y la moda, pero que los discursos de lo bello como mecanismos de lo "deseable" dejan sin registro porque son las estéticas no funcionales a la moda hegemónica. Aunque la moda hegemónica lee estas estéticas otras como ordinarias, feas, vulgares, indeseables, la moda popular produce sus propios referentes y tendencias efímeras cuyo único fin es el consumo aparente. Esta producción es altamente valorada y entendida como moda por las personas que comparte valores sociales, culturales y condiciones económicas dentro de lo popular.

\section{Conclusiones}

La moda popular se compone de gradaciones estéticas que pasan por la reproducción, la adaptación y lo propio, en donde no se renuncia a la hegemonía: existe una negociación constante y problemática en la recepción popular de esa moda. Pero más allá de esa hegemonía, del mero hecho de la emulación o la adaptación 


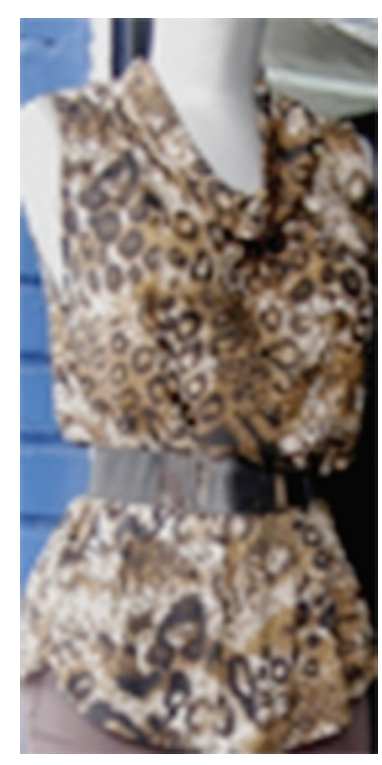

Figura 7. Blusa animal print de la moda popular.

contextual, la moda popular genera sus propios referentes corporales, de apariencia y de práctica del vestido que incluso son incompatibles con los valores hegemónicos, pero que cumplen con todas las premisas de la moda y que están hechos para caducar. La apariencia popular es aceptada en las tiendas, los vendedores y los consumidores de estos objetos quienes, en una cadena autónoma de esta moda otra, validan y ponen a circular ampliamente los valores de la moda popular.

Así, la moda no es un conjunto único de producción, circulación, consumo y adaptación subjetiva desde la hegemonía y en su amplios márgenes, sino que la moda debe decirse en plural y de ello es prueba la moda popular con toda su autonomía. La moda popular ejerce pequeñas hegemonías en los sectores populares (tan numerosos en términos poblacionales que incluso superan cuantitativamente a las clases sociales dominantes) mediante la validación de estándares estéticos indiferentes a la hegemonía en la moda. Lo bello y de lo deseable se reconfiguran hasta tomar connotaciones de completa oposición, recordándonos que la belleza es un concepto contingente a los sujetos y su contexto.

En suma, como los valores de lo popular no se determina unívocamente por las aspiraciones de la hegemonía, es necesario referirse a la moda en plural, las modas. Tal como se ha enunciado hasta ahora, la bibliografía académica da a entender que se trata de un solo discurso. Como la moda no es un texto prescrito, las modas pululan en diferentes expresiones populares, hegemónicas, tradicionales, de época, etcétera, legitimadas de acuerdo al modo en que los individuos y las colectividades desean presentar sus cuerpos. 


\section{Referencias bibliográficas}

Austin, J. (1982). Cómo hacer cosas con palabras. Barcelona: Paidós.

Barthes, R. (2003). El sistema de la moda y otros escritos. Barcelona: Paidós.

Bourdieu, P. (1998). La distinción. Criterios y bases sociales del gusto. Madrid: Taurus.

Bromberg, P. y Gomescásseres, T. (2010). Estado del arte sobre el mundo urbano-popular en Bogotá. Bogotá: Universidad Nacional de Colombia e Instituto Distrital para la Protección de la Niñez y la Juventud (Investigación inédita).

Bummer, H. (1969). Fashion: from class differentiation to collective selection. The Sociological Quarterly, 10(3), 275-291.

Descamps, M. (1986). Psicosociología de la moda. México: Fondo de Cultura Económica.

Douglas, M. (1997). Estilos de pensar. Barcelona: Gedisa.

Elías, N. (1987). El proceso de la civilización. Investigaciones sociogenéticas y psicogenéticas. Madrid: Fondo de Cultura Económica.

García-Canclini, N. (2004). De qué estamos hablando cuando hablamos de lo popular. En Consejo Nacional para la Cultura y las Artes (comp), Antologías sobre cultura popular e indígena (pp. 153-165). México D.F.: Consejo Nacional para la Cultural y las Artes.

Hall, S. (1984). Notas sobre la deconstrucción de lo popular. En S. Ralph (ed.), Historia popular y teoría socialista (pp.93-112). Barcelona: Crítica.

Laclau, E. (1977). Introducción. En P. Anderson (ed.), La cultura represiva. Elementos de la cultura nacional británica (pp. 5-21). Barcelona: Anagrama.

Martín-Barbero, J. (1987). De los medios a las mediaciones. Comunicación, cultural y hegemonía. México: Gustavo Gilli.

Salazar, E. (2009). Valoraciones, tácticas y estrategias: de los juegos del consumo a la moda como libertad. Jóvenes en Bogotá (Tesis de pregrado inédita). Universidad Nacional de Colombia, Bogotá, Colombia.

Salazar, E. (2014). De los textiles a las apariencias. Los tránsitos de la moda en Colombia entre 1970 y 1999 (Tesis de maestría inédita). Universidad de los Andes, Bogotá, Colombia.

Sanin, J. (2008). Estéticas del consumo. Configuraciones de la cultura material. Medellín: Universidad Pontificia Bolivariana.

Silva, A. (2006). Imaginarios urbanos. Bogotá: Arango Editores.

Simmel, G. (2002). Sobre la aventura. Ensayos filosóficos. Península: Barcelona. 